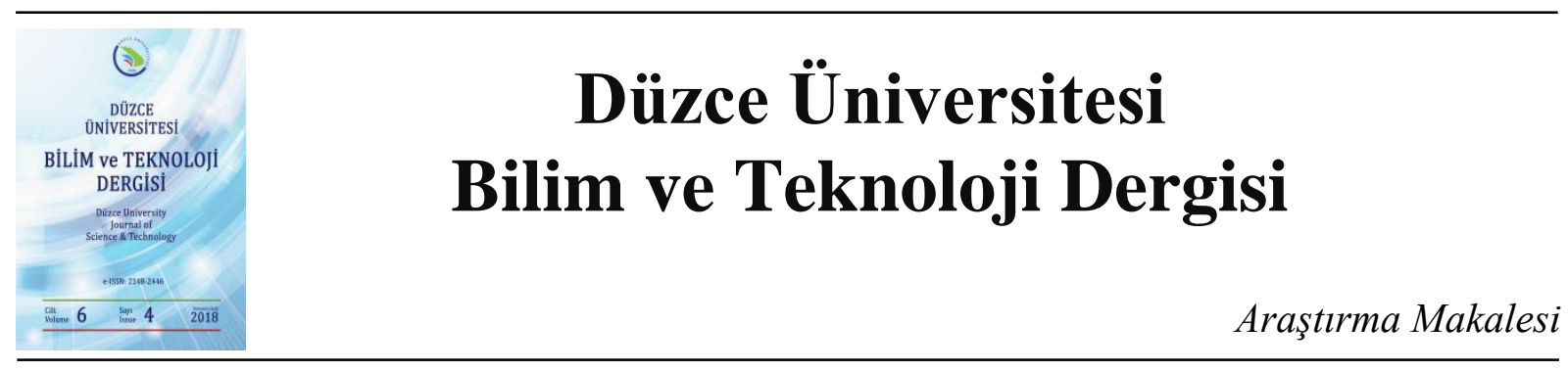

\title{
Katmanlı Üretim İle Elde Üretilmiş Kum Döküm Kalıpların İncelenmesi
}

\author{
Ahmet CAN ${ }^{a, *}$, İbrahim ASLAN ${ }^{b}$ \\ ${ }^{a}$ Endüstriyel Tasarım Bölümü, Mühendislik Fakültesi, Necmettin Erbakan Üniversitesi, Konya, TÜRKIYYE \\ ${ }^{b}$ Makine Mühendisliği Bölümü, Fen Bilimleri Enstitüsü, Necmettin Erbakan Üniversitesi, Konya, TÜRKIYE \\ * Sorumlu yazarın e-posta adresi: ahmetcan@konya.edu.tr
}

\begin{abstract}
$\underline{\text { ÖZET }}$
Hızla gelişen üretim sektöründe, daha verimli ve hızlı üretim metotlarının önemi gittikçe artmaktadır. Son yıllarda ortaya çıkan en önemli üretim metotlardan biri de katmanlı üretim yöntemleridir. Bu çalışmada, yapıştırıcı ile katmanlı üretim yöntemi kullanılarak üretilen kalıpların, kum döküm uygulamalarında kullanılabilirliği hakkında ön çalışma yapılmıştır. Katmanlı üretim yöntemlerinde, geleneksel üretim yöntemlerine göre prototip parçaların üretimi daha hızlı ve daha düşük maliyetli olarak gerçekleşmektedir. Karmaşık ve ters açılı parçaların, alüminyum ve ahşap modelle bile yapılamayacak helisel kavisli ve benzer geometrili içi boş parçaların katmanlı üretim yöntemleriyle kum modelleri yapılarak döküm tekniği ile elde edilmesi mümkündür. Bu çalışmada, döküm kalıp üretimi için ana malzeme olarak geleneksel döküm uygulamalarında kullanılan silis kumu kullanılmıştır. Reçine olarak ise; düşük yüzey pürüzlülüğü, yüksek birleştirme dayanıkl1lığı sağlayan furan reçinesi ve buna uygun katalizör kullanılmıştır. Çalışma için özel olarak üretilen küp ve çubuk şeklindeki kalıplara, istenilen katman kalınlığında silis kumu serilmiş ve kumun üzerine sertleştirici, reçine elle püskürtülmüştür. Bu işlemler, istenilen ölçüler sağlanıncaya kadar devam etmiştir. Sonrasında üretimi yapılan küp ve çubuk numunelerin basma ve eğme testleri yapılarak mekanik özellikleri incelenmiştir. Daha sonra ise, kum tane boyutunun mekanik özelliklere etkisi incelenmiştir. Yapılan bu çalışmada, ileride imal edilmesi düşünülen yapıştırma katmanlı 3B yazıcının yazılımına ait imalat parametreleri ve algoritması ile çalışma sistematiğini belirlemede kullanılmak üzere ön bilgiler elde edilmiştir.
\end{abstract}

Anahtar kelimeler: Yapıştırıcı ile katmanlı üretim, Furan reçine, Katmanlı imalat, Kum kalıp.

\section{Investigation of Sand Casting Molds Hand-Made Manufactured by Layered Manufacturing}

\footnotetext{
ABSTRACT

In the rapidly developing manufacturing sector, the importance of more efficient and faster production methods is increasing. One of the most important manufacturing methods emerged in recent years is also layered

Geliş: 31.05.2018, Düzeltme: 14.06.2018, Kabul: 01.07.2018

* The third International Congress on 3D Printing (Additive Manufacturing) Technologies and Digital Industry (3D-PTC2018) kongresinde sunulmuş ve özet basılmıştır.
} 
manufacturing methods. In this study, the preliminary study about the usability of the molds produced by using manufacturing method of binder jetting in sand casting applications has been done. The production of prototype parts with the layered manufacturing methods according to the traditional manufacturing methods is carried out faster and less costly. By using layered manufacturing methods, it is possible to obtain the hollow parts with complex curves and reverse angles with helical curves and similar geometries which cannot be made even with traditional aluminum and wood models. In this study, silica sand was used as the primary material for casting mold production. Furan as the resin which provide low surface roughness and high bond strength was used and suitable catalyst for this resin was used. It was produced cube and bar molds for the study. The silica sand was laid on specific layer thicknesses to these molds and the hardener and resin were sprayed on the sand. These processes continued until the required dimensions were provided. Afterwards, compression and bending tests of cube and bar specimens were realized and their mechanical properties were investigated. Then, the effects of different sand particle size on mechanical properties were investigated. In this study, preliminary information was obtained to be used in determining the working system by manufacturing parameters and algorithm of the software of the binder jetting $3 \mathrm{~d}$ printer which is considered to be manufactured in the future works.

Keywords: Binder jetting, Furan resin, Layer manufacturing, Sand model.

\section{GiRIS}

$3_{\mathrm{b}}^{\mathrm{B}}$ B baskı, bir yazıcı kafası, nozul veya bir diğer yazıcı teknolojisi kullanılarak malzemelerin biriktirilmesi yoluyla model veya parça imalatıdır. Katmanlı imalat yöntemi ise, 3B model verilerinden nesneler üretmek için malzemeleri, çıkarmalı üretimin tersi olarak tabaka üzerine tabaka üretimi prosesiyle bağlama yöntemidir [1].

Genellikle 3B baskı yöntemi, katmanlı imalat yöntemi olarak adlandırılır fakat aslında 3B baskı yöntemi, katmanlı imalat yönteminin alt sınıfıdır. 3B baskı, genellikle düşük maliyet kategorisinde çoğunlukla tüketici odaklı makine tiplerinin alt sınıflarıyla ilişkilendirilir [2].

3B baskı teknolojileri, yeni bir ürün tasarlayıp geliştirme aşamasında meydana gelebilecek her türlü problemin önceden görülmesi ve bu problemlerin çözümünü sağlayacak yolların bulunmasını hızlandırır. Dijital ortamda tasarlanan her bir ürünün seri üretime geçmeden önce prototipinin üretilmesi ve gerekli testlerin yapılması gerekir. Geleneksel yöntemde, prototip hazırlama işlemi hem maliyetli hem de uzun zaman alır. 3 boyutlu baskı yönteminde ise, bu prototipler kısa zamanda üretilir. Aynı zaman da, elde edilen prototiplerin gerekli testleri yapılarak incelenebilir. Değerlendirme sonucunda tasarım kolayca değiştirilebilir ve yeniden üretilebilir. Sonuç olarak daha az maliyetle ve daha hızlı prototipler elde edilebilir [3].

3B baskı teknolojileri yönteminde, geleneksel yöntem göre fire kaybı azdır. Böylece üretim maliyetleri azalır. Tasarımı yapılabilen karmaşık parçalar üretilebilir, ürün ağırlığı azaltılabilir, 3 boyutlu baskı teknolojileri; dişçilik, mimarlık, havacılık-uzay, medikal, ilaç, giyim, gıda, döküm, otomotiv sektörleri vb. birçok alanda kullanılmaktadır.

3B baskı teknolojisi tıp alanında farklı cihaz veya ekipmanlara entegre edilebilirliği ve kullanımı artmaktadır. Çeşitli yaralanmalar sonucu bazı insanlara implant takma ihtiyacı meydana gelebiliyor. $\mathrm{Bu}$ alanda yapılmış bir çalışmada, kafasına darbe almış bir hastanın kafatası, bilgisayarlı tomografisi 
çekilerek elde edilen görüntünün verileri dijital ortamda tekrar düzenlenmiş ve bu veriler kullanılarak 3B yazıcı ile hastanın kafatasının bir modeli yazdırılmıştır. Ayrıca hasarlı olan bölgeye uygun biyouyumlu malzemeden protez tasarlanmıştır. Bu çalışmadaki gibi bir tasarım sürecinin hasta üzerindeki operasyon süresini azaltabileceği ve hasarlı bölgeye daha az müdahale ile implant kontrolünün operasyon öncesi yapılabileceği görülmüştür [4].

Eklemeli imalat teknolojisinin kullanım yerlerinden biride eğitim ortamıdır. Bu teknolojinin eğitim ortamında kullanılması ile öğrenciler kendi fikirlerini somut modellere aktarıp, hayal güçlerinin gelişebileceği ön görülmektedir. Böylece, eklemeli imalat teknolojilerinin eğitimindeki teknik, sağlik ve sosyal bilimler alanlarında kullanılabileceği, bunun sonucunda öğrencilerin daha becerili, teknik ve donanımlı hale gelerek ülkenin gelecek sanayi strateji hedeflerine ulaşmasında olumlu etkisi olacağı düşünülmektedir [5].

Güler ve Çetinkaya [6] ise endüstriyel boyutlarda kartezyen tipi ve çift baskı kafasına sahip FDM (Fused Deposition Modelling) yöntemi ile çalışan üç boyutlu yazıcı tasarımı ve prototipi yapmışlardır. Sonrasında böyle bir yazıcıda yazdırma hızı ve katman kalınlığının üretim kalitesine etkisi araştırılmıştır.

Elbaba vd., [7] ise esnek ürün elde edilmesi için katmanlı imalat teknolojisinde malzeme seçimi ve imalat parametreleri ile ilgili gerekli ön şartları araştırmışlardır. Çekme dayanımı, sertlik, elastisite modülü gibi mekanik özellikler dikkate alınarak, kullanılacak uygulama gereksinimlerine göre polimerik malzeme seçimi yapılması gerektiği tespit edilmiştir. Eriyik yığma tekniği kullanılarak esnek polimerik filament ile imalat parametreleri belirlenmiştir.

3B baskı üretiminin büyük avantajına rağmen, seri üretime göre yavaş olması, standart ürün kalitesi olmaması, kısıtlı malzeme seçeneği gibi sebeplerden dolayı üreticiler bu üretimi genellikle prototip üretme aracı olarak kullanmaktadır. Son yıllarda 3B baskıda gelişen gelişmeler sonucunda artan ürün kalitesi sebebiyle, bu üretim yönteminin son ürün imal etmede kullanımı artmıştır.

Döküm kum kalıbı üretmek için kullanılan çeşitli katmanlı imalat yöntemleri vardır. Bunlardan bazıları, Seçici Lazer Sinterleme, Stereolithografi, Tabakalı Cisim Yığma, Eritilmiş Malzeme Yığma, Malzeme Jeti ve özellikle Yapıştırıcı ile Katmanlı İmalat (3B Baskı) döküm kum kalıp ve modellerinin yapımında en çok kullanılan katmanlı imalat yöntemleridir.

Yapıştırıcı ile katmanlı imalat yönteminin ASTM standartlarına göre ilk örneğini, Emanuel Sachs, Massachusetts Teknoloji Enstitüsü (MIT) üniversitesinde 1989 y1lında icat etmiştir, 1993 yılında patenti alınmıştır. Daha sonra bu teknolojinin patenti 1995 yılında Z Corporation tarafından elde edilmiştir [8].

Genelde kalıp imalatı için kullanılan Yapıştırıcı ile Katmanlı İmalat yönteminde, toz materyal üzerine, mürekkepli yazıcılar benzeri hareketli bir kafa ile yapıştırıcı uygulanır ve üzerine yeni materyal katmanı serilerek sertleştirilir. Yapıştırıcı ana tutucu olduğundan genel olarak daha kırılgan çözümler gerçekleştirilir [9].

Şekil 1 (a) ve (b)'de toz tabanlı 3B yazıcının üretim süreci şematik olarak gösterilmiş ve Şekil 2'de ise üretim basamakları verilmiştir. 
(a)
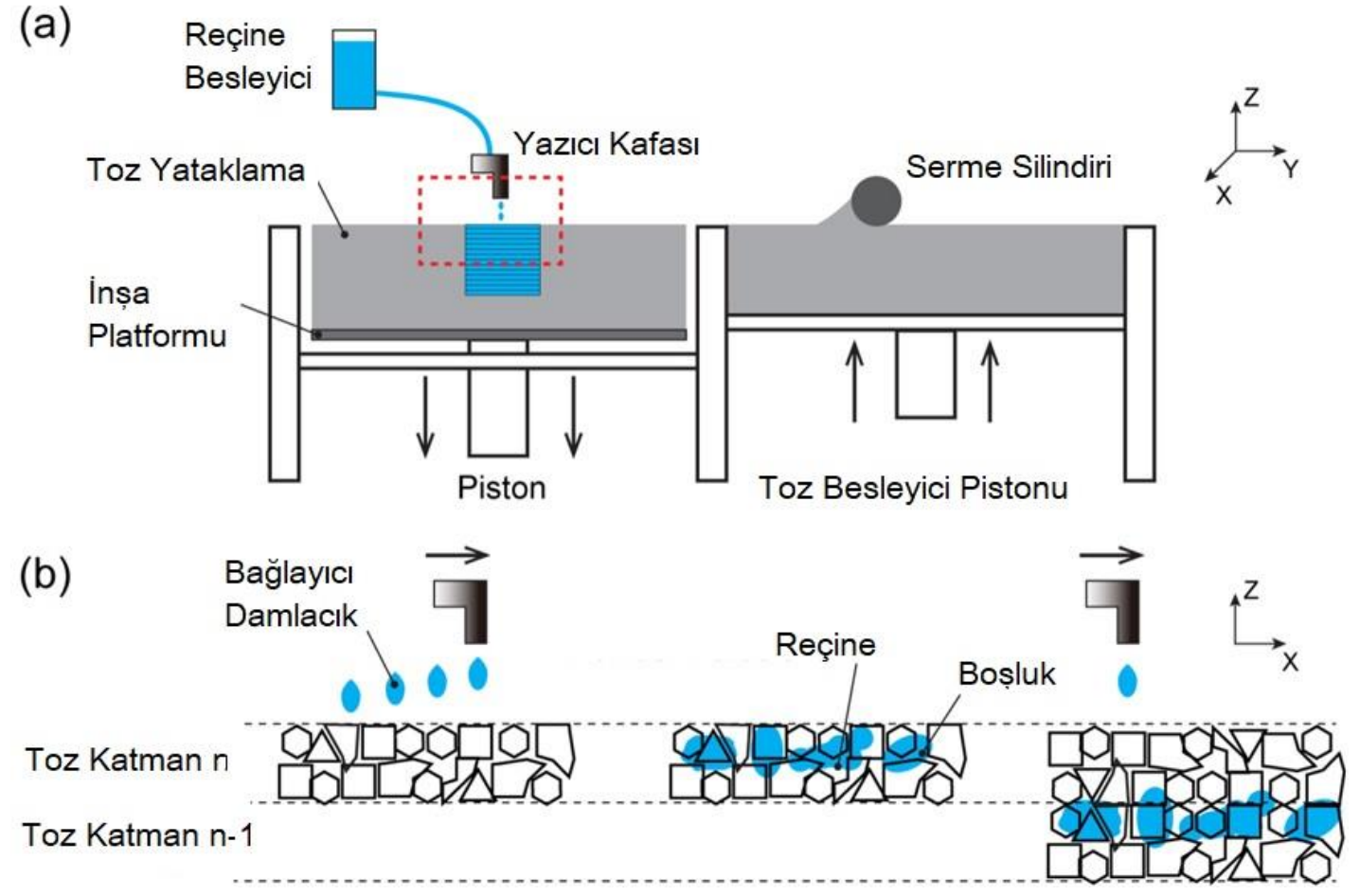

Şekil 1. 3B yazıcının üretim şeması: (a) 3B yazıcı mürekkep püskürtme baskı sistemi, (b) Kırmızı dikdörtgen alanin genişletilmesi: Bitişik tabakalar arasındaki toz / bă̆layıcı etkileşimi [10].

Şekil 1'de gösterildiği üzere; başlangıçta, yazıcı kafası ile birlikte takılı toz yayıcı silindir, inşa platformunun tabanını kaplamak için toz katmanı sermiştir. Taban katmanı yaklaşık $3 \mathrm{~mm}$ kalınlıktadır. Daha sonra 3B yazıcının katman kalınlık ayarlarına göre, yaklaşık olarak 0,1 mm kalınlığında ince bir katman serilmiş ve toz yatağının yüzeyi toz yayıcı silindir tarafından düzleştirilmiştir. Bir tabaka tamamlandıktan sonra bağlayıcı solüsyon yazıcı kafasına, bağlayıcı besleyicisinden iletilmekte ve yazıcı kafasına bağlı nozul tarafindan püskürtülmektedir. Bağlayıcı solüsyonun kontrolünü sağlayan mekanizma, isteğe bağlı damla (DoD) olarak adlandırılan sürekli olmayan yaklaşımdır. Modern masaüstü yazıcı sistemlerinde yaygın bir şekilde kullanılmaktadır. Yazıcı kafasındaki bağlayıcı solüsyon, nozuldan dışarı doğru piezoelektrik aktüatör tarafından mekanik olarak ya da termal kabarcık tarafindan termal olarak itilmektedir. Daha sonra bağlayıcı damlacıklar oluşur ve toz katmanlarına selektif olarak uygulanır, toz partiküllerinin birbirine yapışmasını sağlar. Yukarıda belirtilen adımlar tekrar edilir, inşa edilmiş parçalar tamamlanır. Özel kuruma süresi beklenildikten ve bağlanmamış tozlar hava üfleyici kullanılarak çıkarıldıktan sonra parçalar çıkarılır [10].

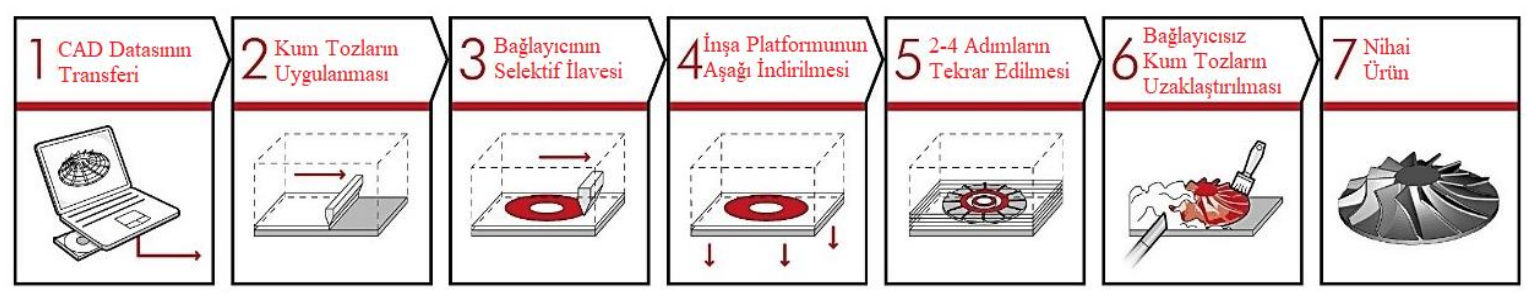

Şekil 2. 3B baskı proses basamakları [11]. 
Yapıştırıcı ile katmanlı imalat yöntemi, metal, seramik ve kum gibi çeşitli malzemeleri yazdırma kapasitesine sahiptir. Kum gibi bazı malzemeler ilave işlem gerektirmez. Diğer malzemeler sıklıkla kürleme, sinterleme gibi ilave işlemlere ihtiyaç duyarlar. Yapıştırıcıyla katmanlı imalat yönteminde, katı katmanlar üretilmesi, üretimde parçalar gevşek toz ile desteklendiği için ayrıca kalıba ihtiyaç duyulmaması, çok büyük boyutlu, karmaşık şekilli parçalar üretilebilmesi, üretim sırasında 1sı kaynağı kullanılmadığı için üretilen parçalarda kalıcı ısıl gerilmeler oluşturmaması ve diğer katmanlı imalat yöntemlerine göre daha uygun maliyetli üretimi mümkündür [12].

Şekil 3 ve Şekil 4'de gösterildiği üzere, Yapıştırıcı ile katmanlı imalat yöntemiyle, prototip ürünler, nihai ürünler ve döküm kalıpları üretilebilir.

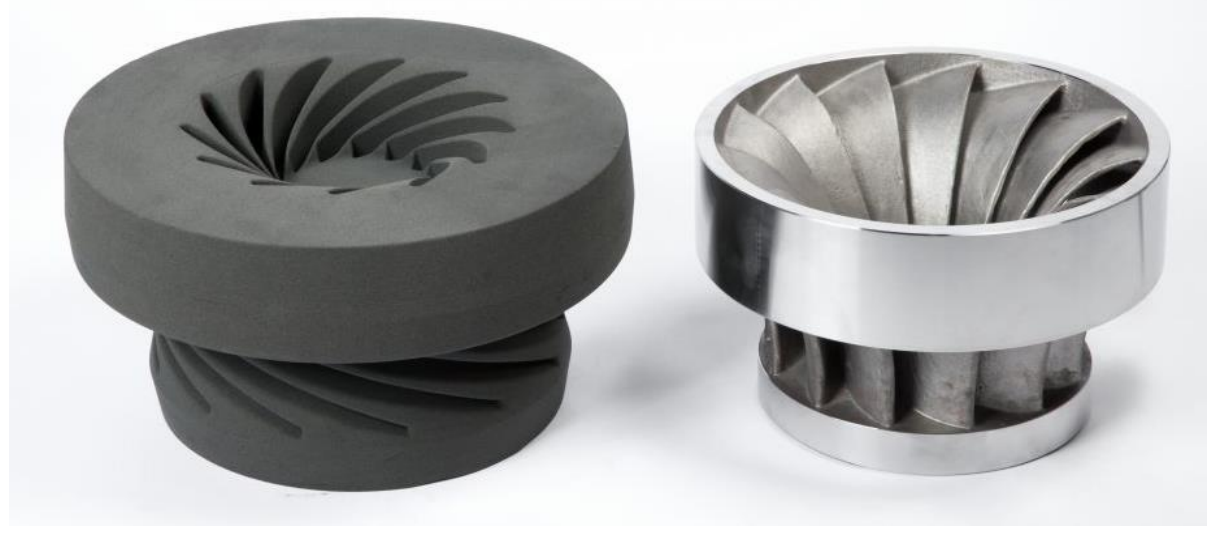

Şekil 3. 3B baskı yöntemiyle üretilmiş kum kalıp modeli ve metal pervane [11].

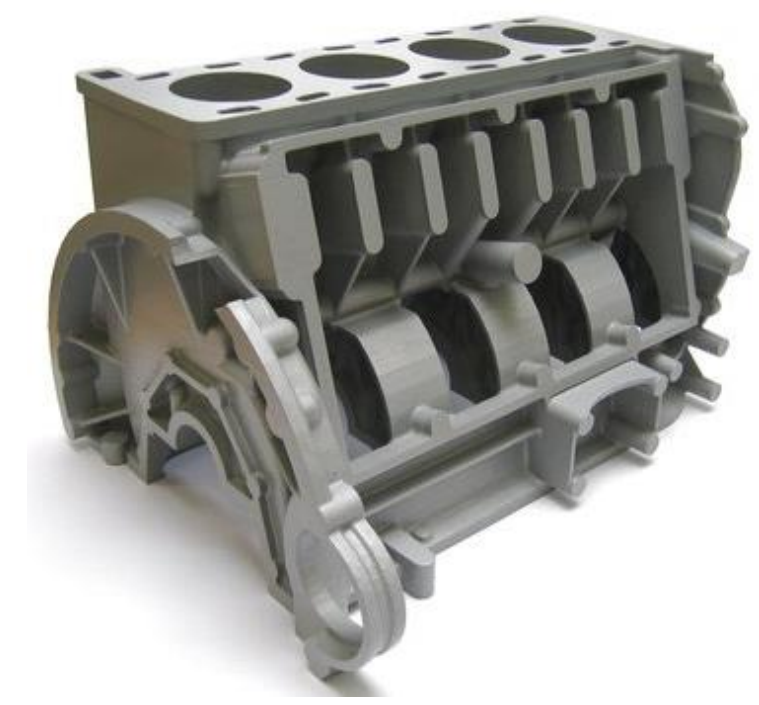

Şekil 4. 3B yazıcı ile tek parça halde basılmış motor bloğu [13].

Bu çalışmada, yapıştırma ile katmanlı imalat metoduna göre döküm uygulamaları için kullanılabilecek kum kalıp üretimine ait imalat parametreleri ile çalışma sistematiğini belirlemede kullanılmak üzere ön bilgiler elde edilmiştir. Ön görülen çalışma sayesinde ilerde üretilecek $3 \mathrm{~d}$ printer ile ahşap ve alüminyum model kullanmadan direk döküme hazır kum model üretilebilmesinin alt yapısı oluşturmay1 hedeflemekteyiz. 
Küp ve çubuk numunelerin üretimi yapılırken, farklı kum tane boyutları seçilerek, bu parametrenin mekanik özellikleri etkisi incelenmiştir.

\section{MATERYAL}

$\mathrm{Bu}$ çalışmada, yapıştırıcı ile katmanlı imalat yöntemine göre silika kum, havada sertleşen reçine türlerinden olan furan reçine ve bu reçineye uygun katalizör kullanılarak, küp ve çubuk şeklinde numuneler üretilmiştir ve bu numunelerin mekanik özellikleri incelenmiştir.

Yapılan bu çalışmada, ileride üretilmesi düşünülen yapıştırma katmanlı 3B yazıcının çalışma sistematiğini ve yazıcının çalışma algoritmasına belirlemede kullanılacağı için, 3B yazıcı üretilmemiş yalnızca, yapıştırıcı ile katmanlı imalat yöntemi kullanılarak küp ve çubuk şeklinde numuneler üretilmiştir. Döküm kum kalıp üretimde ana malzeme olarak, döküm endüstrisinde çokça kullanılan, düşük maliyetli, farklı tane boyutlarında Silis kumu kullanılmıştır. Yapıdaki kumları bağlamak için ise furan reçinesi kullanılmıştır. Furan reçinesi, düşük yüzey pürüzlülüğü, yüksek birleştirme dayanıklılığı, işlem sonrası sinterlemeye gerek olmaması, düşük maliyetli, serbest kumun geri dönüştürülebilmesi gibi avantajları vardır. Çalışmada, reçinenin sertleşmesi için uygun katalizör kullanılmıştır.

Çalışma için özel olarak küp ve çubuk şeklinde kalıplar üretilmiştir. Bu kalıplara, istenilen katman kalınlığında silis kumu serilmiş ve bu kumları birbirlerine bağlamak için kumun üzerine sırasıyla sertleştirici, reçine püskürtülmüştür. Bu işlemler, istenilen ölçüler sağlanıncaya kadar tekrar edilmiştir. Döküm kum kalıp numunesi üretiminde kullanılan malzemeler Tablo 1'de verilmiştir.

Tablo 1. Döküm kum kalıp numunesi üretiminde kullanılan malzemeler [14-15].

\begin{tabular}{ccc}
\hline Toz Türü & $\begin{array}{c}\text { Ortalama Tane İriliği } \\
(\mu \mathrm{m})\end{array}$ & AFS Numarası \\
\hline Silika Kum & $240-270$ & $55-60$ \\
& $330-390$ & $40-45$ \\
& $450-600$ & $30-35$ \\
\hline Reçine Türüi & Katalizör (Serter) & Isıl İşlem \\
\hline Furanol CS 470 Reçine & CS 30 & Is1l işlem gerekli olmadı̆̆ \\
(Furan Reçinesi) & & için yapılmamıştır. \\
\hline
\end{tabular}

\section{METOT}

Bu çalışmada, öncelikle CNC tezgahında, üretilmesi kararlaştırılan küp ve çubuk şeklindeki numunelere uygun kalıplar üretilmiştir. Ayrıca, yüzeyi oldukça düzgün bir alt tabla üretilmiştir. Sonrasında, silika kumlar, alt tablaya düzgün bir şekilde belli oranda serilmiştir. Tabaka kalınlığı $3 \mathrm{~mm}$ olacak şekilde serilen silika kumların üzerine her katman sonrası, istenilen kalıp şekline göre katalizör ve reçine sırasıyla manuel olarak püskürtülmüştür. Üretimde uygulana bu işlemler 4 defa tekrar edilerek, istenilen 
numune kalınlığı katman katman elde edilmiştir. Numunelerin katmanların tamamen kürlenmesi için oda sıcaklığında 12 saat bekletilmiştir. Sonrasında üretimi yapılan küp ve çubuk numunelerin basma ve eğme testleri yapılarak mekanik özelliklere, kum tane boyutunun etkisi incelenmiştir. Ağırlıça kumreçine/katalizör oranları, ön denemeler sonucu belirlenmiştir ve Tablo 2'de değerleri verilmiştir.

Tablo 2. Ağırlıkça kum-reçine ve katalizör oranları

\begin{tabular}{cccc}
\hline Kum Çeşidi & Ağırlıkça Reçine Oranı & $\begin{array}{c}\text { Ağırlıkça Katalizör } \\
\text { Oranı }\end{array}$ & Ağırlıkça Kum Oranı \\
\hline $30 / 35$ & $\% 24$ & $\% 6$ & $\% 70$ \\
$40 / 45$ & & & \\
$55 / 60$ & & & \\
\hline
\end{tabular}

Üretim yapılırken furan reçinesi ve katalizör birbirlerine doğrudan karıştırılmamıştır. Şayet direk temas edilmesi durumunda şiddetli ekzotermik reaksiyon oluşmaktadır. Bu sebeple katalizör ve reçine kuma ayrı ayrı pulverize şekilde püskürtülmüştür.

\section{DENEY SONUÇLARI}

Üretimi yapılan 3 farklı kum tane kalınlığına sahip çubuk döküm kum kalıp numunelerinin görüntüleri Şekil 5 (a), (b) ve (c)'de verilmiştir. Bu numunelerin göz ile muayenesi yapıldığında 30/35 numunesinin diğer numunelere göre dış yüzeyinde daha fazla gözenek olduğu görülmektedir.

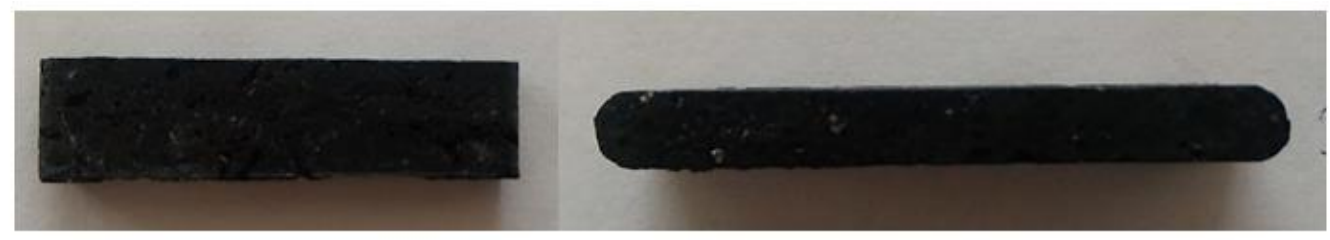

(a)

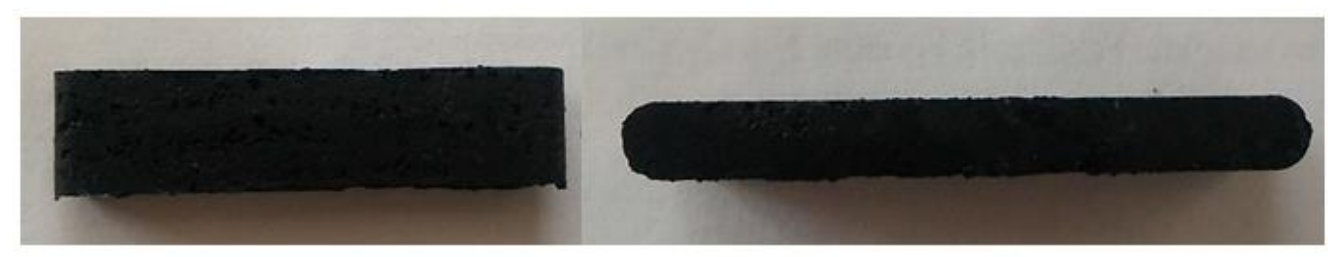

(b)

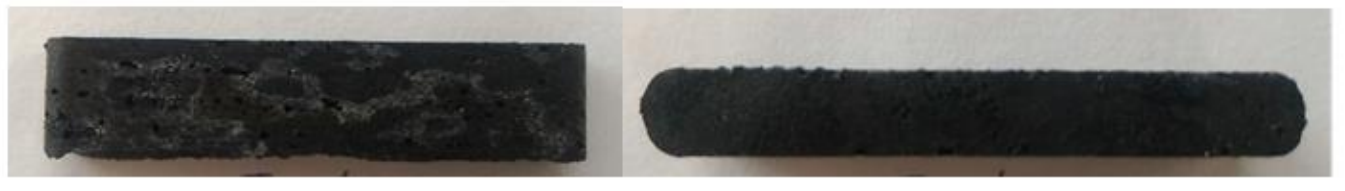

(c)

Şekil 5. Üretilen çubuk döküm kum kalip numuneleri, (a) 30/35 numunesi, (b) 40/45 numunesi, (c) 55/60 numunesi 
Üretilen numunelerin gözeneklilik oranları; boşluk hacminin, toplam hacme oranı hesabına göre yapılmış ve Tablo 3'de verilmiştir.

Tablo 3. Numunelerin gözeneklilik oranları

\begin{tabular}{cc}
\hline Numuneler & Gözeneklilik Oranları \\
\hline $30 / 35$ & $\% 13,6$ \\
\hline $40 / 45$ & $\% 8,9$ \\
\hline $55 / 60$ & $\% 7,5$ \\
\hline
\end{tabular}

Gözeneklilik sonuçlarına göre, en gözenekli numunenin \%13,6 oranla en büyük kum tane boyutuna sahip 30/35 numunesi olduğu bulunmuştur. En küçük kum tane boyutuna sahip 55/60 numunesinin ise gözeneklilik oranı $\% 7,5$ bulunmuştur. 40/45 numunesinin ise gözeneklilik oranı $\% 8,9$ 'dur.

$\mathrm{Bu}$ sonuçlarına göre, malzeme yapısını oluşturan bileşenlerden biri olan kumun, tane boyutunun azalmasıyla, numunenin gözeneklilik oranının da azalmakta olduğu bulunmuştur. Bu durumunda, numune yapısını oluşturan kumun tane boyutu ne kadar büyük olursa, numune yapısında daha büyük boşluklar oluşmasına neden olmaktadır.

Üretimi yapılan küp döküm kum kalıp numunelerinin mekanik özelliklerinin belirlenmesi için ilerleme hızı 500N/sn seçilerek basma testi yapılmıştır. Üretilen çubuk döküm kum kalıp numunelerin mekanik özelliklerinin belirlenmesi için ise, ilerleme hızı $2 \mathrm{~N} / \mathrm{sn}$ seçilerek 3 noktadan eğme testi yapılmıştır. Çubuk döküm kum kalıp numunenin eğme testi sırasında çekilmiş görüntüsü Şekil 6'da verilmiştir. Basma ve eğme testi, Shimadzu AG-X marka 100 kN kapasiteli cihazla yapılmıştır.

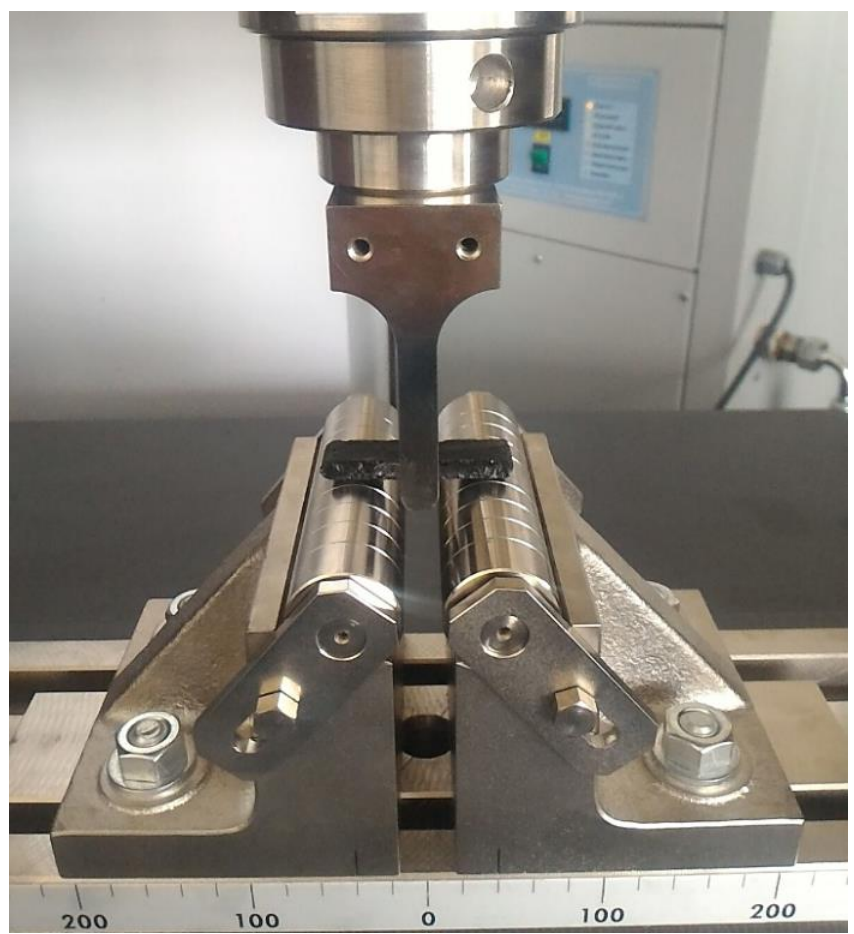

Şekil 6. Ĕgme testi sirasinda çubuk döküm kum kalıp numunesi 


\section{A. BASMA TEST SONUCU}

Bu çalışmada üretilen küp döküm kum kalıp numunelere basma testi yapılarak, basma yükü altındaki dayanımlarını belirlenmiştir. Basma test sonucunda, basma gerilmesi-şekil değiştirme grafiği elde edilmiştir. Bu grafik Şekil 7’de verilmiştir.

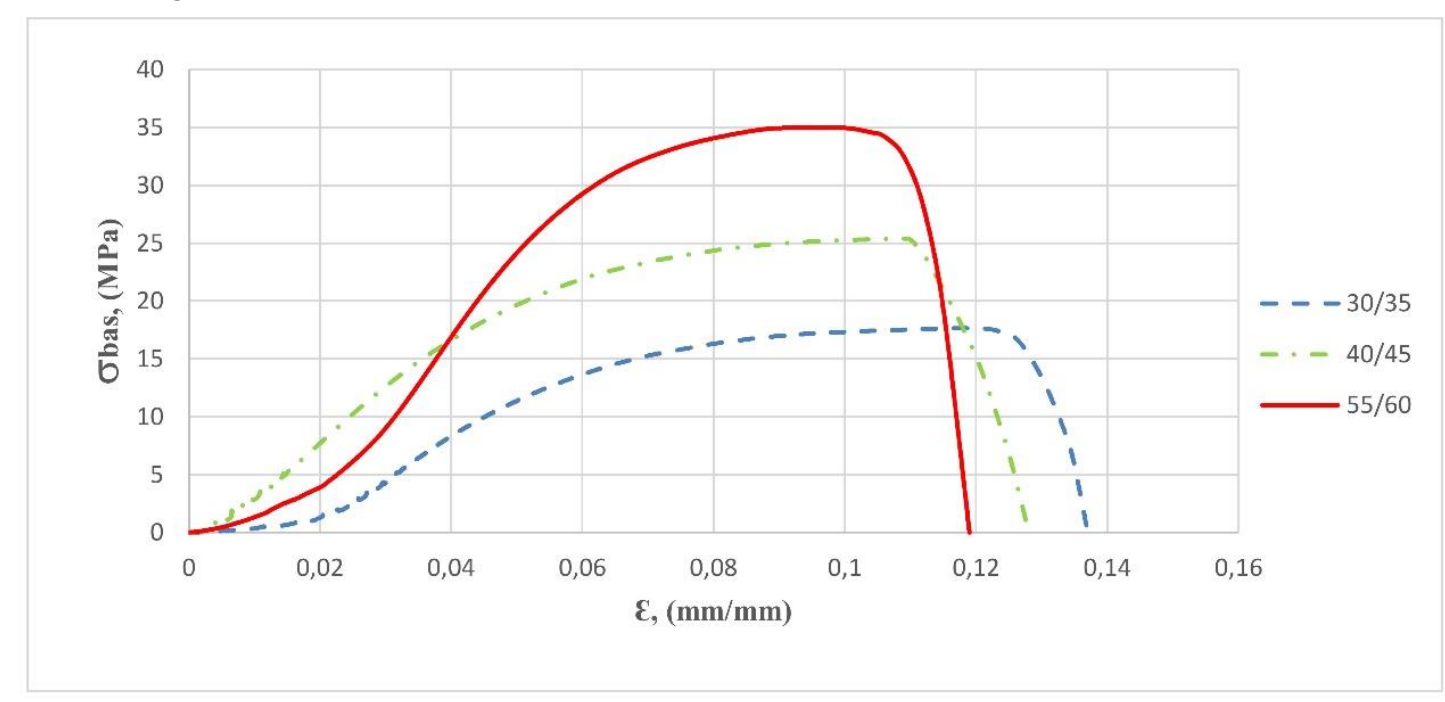

Şekil 7. Basma gerilmesi-şekil değiştirme grafĭgi

Basma test sonucunda, en büyük basma gerilmesine ve en az birim şekil değiştirme değerine sahip numunenin $\sigma_{\text {bas }, 55 / 60}=34,98 \mathrm{MPa}, \varepsilon_{55 / 60}=0,119$ ile 55/60 numunesi olduğu bulunmuştur. En küçük basma gerilmesine ve en büyük birim şekil değiştirme değerine sahip numunenin ise, $\sigma_{\text {bas } 30 / 35}=17,67 \mathrm{MPa}$, $\varepsilon_{30 / 35}=0,137$ ile 30/35 numunesinin olduğu bulunmuştur. 40/45 numunesinin basma gerilmesi $\sigma_{\text {bas }, 40 / 45}=25,40 \mathrm{MPa}$ ve birim şekil değiştirme değeri $\varepsilon_{40 / 45}=0,128$ olarak bulunmuştur.

Basma gerilmesi ve şekil değiştirme değerlerine bakıldığı zaman çıkan sonuçlardan birisi, kum tane boyutunun azalmasıyla numunenin basma dayanımı artmakta, numunenin birim şekil değiştirme değeri ise azalmaktadır.

$\mathrm{Bu}$ durumun sebebi, numuneyi oluşturan bileşenlerden biri olan kumun tane boyutunun azalmasıla yapıdaki gözeneklilik oranının azalması ve bunun sonucunda numunenin mukavemetini artmaktadır. Ancak, yapıdaki gözenekliliğin az olmasında ise, basma testi sırasında uygulanan yük arttıkça yapıyı oluşturan kum tanelerin boşlukta kayması zorlaşmakta ve bunun sonucunda numunenin birim şekil değiştirme değeri azalmaktadır. Böylece yapının sünekliği de azalmış olmaktadır.

\section{B. EĞME TEST SONUCU}

Bu çalışmada üretilen çubuk döküm kum kalıp numunelere 3 noktadan eğme testi yapılarak, yük altındaki eğme dayanımları belirlenmiştir. Eğme test sonucunda, kuvvet-yer değiştirme ve maksimum eğme gerilme grafiği elde edilmiştir. Bu grafikler Şekil 8-Şekil 9'da verilmiştir. 


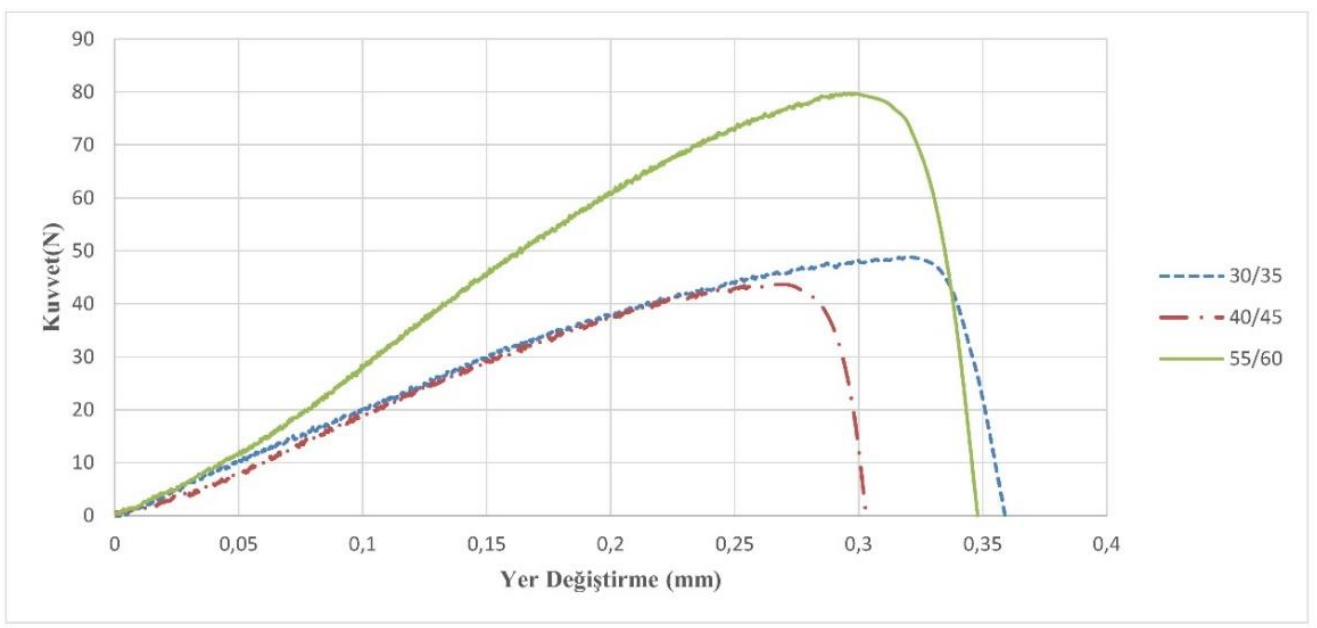

Şekil 8. Kuvvet-yer değisştirme grafiği

Eğme testi sonucunda, 55/60 numunesinin, diğer numunelere göre daha yüksek kuvvette kırıldığ1 görülmüştür. 55/60 numunesinin dayandığ 1 maksimum eğme kuvveti, $F_{55 / 60}=79,67 \mathrm{~N}$ olarak bulunmuştur. Diğer numunelerin maksimum eğme kuvvetleri ise, $F_{30 / 35}=48,98 \mathrm{~N}$ ve $F_{40 / 45}=43,58 \mathrm{~N}$ olarak bulunmuştur. Bu durum, numuneler arasında eğme dayanımı en yüksek olan malzemenin 55/60 numunesi olduğunu göstermektedir. 55/60 numunesinin dayanıklılığının yüksek olmasının sebebinin, gözenekliliğinin daha az olması ve 1slatılabilirliğinin yüksek olmasından kaynaklandığı düşünülmektedir.

Eğme testi yapılan numunelerin sahip olduğu sehim miktarları karşılaştırıldığında, en büyük sehim miktarına sahip numunenin $\delta_{30 / 35}=0,359 \mathrm{~mm}$ ile $30 / 35$ numunesinin olduğu bulunmuştur. Diğer numunelerin sehim miktarları ise, $\delta_{55 / 60}=0,348 \mathrm{~mm}$ ve $\delta_{40 / 45}=0,303 \mathrm{~mm}$ olarak bulunmuştur.

$\mathrm{Bu}$ durum, numuneler arasında en sünek malzemenin 30/35 numunesi olduğunu göstermektedir. Numuneler içerisinde gözenekliliği en yüksek numune olmasına rağmen, 30/35 numunesinin sünekliliğinin daha yüksek olmasının sebebinin, 30/35 numunesinde bulunan gözenekler içerisine kolayca giren reçine ve katalizörün kimyasal tepkimeye girerek gözenek çeperlerine iyi bir şekilde yapışmasından kaynaklandığı düşünülmektedir.

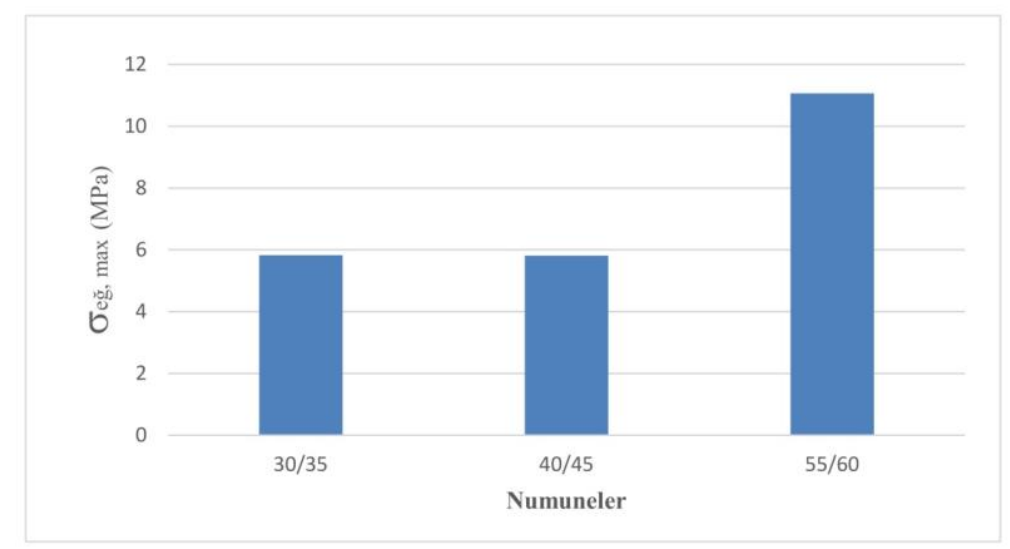

Şekil 9. Numunelerin maksimum ĕgme gerilmeleri 
3 noktadan eğme testi sonucunda, en büyük eğme gerilmesine sahip numunenin $\sigma_{\text {eğ,55/60 }}=11,06 \mathrm{MPa}$ ile $55 / 60$ numunesi olduğu bulunmuştur. $30 / 35$ ve 40/45 numunelerinin eğme gerilmelerinin ise, birbirlerine yakın olduğu, $\sigma_{\text {eğ }, 30 / 35}=5,82 \mathrm{MPa}$ ve $\sigma_{\text {eğ,40/45 }}=5,81 \mathrm{MPa}$ olarak bulunmuştur.

Numunelerin maksimum eğme dayanımlarına bakıldığı zaman çıkan sonuç, kum tane boyutu en az olan 55/60 numunesinin, en büyük eğme dayanımına sahip olduğudur. 55/60 numunesinin maksimum eğme dayanımını, yaklaşık olarak 30/35 ve 40/45 numunelerinin \%90 kadar daha fazladır.

$\mathrm{Bu}$ durumun sebebinin, 55/60 numunenin gözeneklilik oranının daha az olması sebebiyle daha mukavemetli olması ve 55/60 numunesini oluşturan kumun furan reçinesi tarafindan sslatılabilirliğinin iyi olmasından kaynaklandığı düşünülmektedir.

Üretilen, $30 / 35$ ve 40/45 numunelerinin maksimum eğme dayanımlarının birbirlerine yakın çıkma sebebinin, her iki numuneyi oluşturan kum tanelerinin 1slatılabilirliğinin birbirlerine yakın olmasından ve belirli bir tane çapından sonra kum tane boyutunun maksimum eğme dayanım değerini çok fazla etkilememesinden kaynaklandığı düşünülmektedir.

Yapılan bu çalışmadan çıkan sonuçların karşılaştırılabilmesi için literatürde benzer çalışmalar incelenmiştir. Bu çalışmalardan bazıları aşağıda verilmiştir.

Reis [16] ise tekstil atıklarının polimer katkılı betonların mekanik özelliklerine etkisini basma ve eğme testi yaparak incelemiştir. Çalışma sonucunda, epoksi reçine ve kuartz kum kullanılarak üretilen ve reçine- kum oranı 10/90 olan tekstil atı̆̆ içermeyen numunenin eğme mukavemeti 19,43 MPa, basma mukavemeti 31,70 MPa olarak bulunmuştur. Ayrıca, çalışma sonucunda, epoksi reçine ve kuartz kum kullanılarak üretilen ve reçine- kum oranı $12 / 88$ olan tekstil atığı içermeyen numunenin eğme mukavemeti 24,27 MPa, basma mukavemeti, 46,24 MPa olarak bulunmuştur.

İnan ve Yazıcı [17] ise farklı kür koşullarının polimer katkılı harçların eğilme ve basınç dayanımına etkisini incelemiştir. Polimer katkılı harç karışımlarında polimerler, çimento yerine kullanılmıştır. Çalışma sonucunda, stiren-akrilik polimer reçine- kırma kireçtaşı agregası kullanılarak ve reçine-agrega oranı 10/90 olan numune etüv-havada kürlenmiş ve 7 gün sonunda, eğme mukavemeti 7,1 MPa, basma mukavemeti $32 \mathrm{MPa}$ olarak bulunmuştur. Ayrıca, çalışma sonucunda, stiren-akrilik polimer reçinekırma kireçtaşı agregası kullanılarak ve reçine-agrega oranı 15/85 olan numune etüv-havada kürlenmiş ve 7 gün sonunda, eğme mukavemeti $6,8 \mathrm{MPa}$, basma mukavemeti $30,5 \mathrm{MPa}$ olarak bulunmuştur.

Mani vd., [18] ise epoksi ve poliester reçinelerden üretilmiş polimer katkılı betonların mekanik özelliklerini karşılaştırmıştır. Çalışma sonucunda, silis kumlu poliester reçineli polimer betonun basma mukavemeti $53 \mathrm{MPa}$, eğme mukavemeti 13,9 MPa bulunmuştur. Ayrıca, silis kumlu epoksi reçineli polimer betonun basma mukavemeti $97,7 \mathrm{MPa}$, eğme mukavemeti 21,6 $\mathrm{MPa}$ bulunmuştur.

\section{SONUCLLAR}

$\mathrm{Bu}$ çalışmada, bir döküm kalıbında kullanılabilecek mukavemete sahip numuneler elde edilmesi, bu çalışmadan elde edilen sonuçların başarılı olduğunu göstermektedir. Deneysel parametreler içerisinde aşağıda verilen sonuçlar elde edilmiştir. Bu sonuçların ileride tasarlanacak $3 \mathrm{~d}$ yazıcının tasarımında ve üretim parametrelerinin seçiminde 1şık tutacağı ön görülmektedir. 
- Çalışmadan çıkarılan sonuçlara göre, üretimde kullanılan silis kumlarının, reçine ve katalizörün, $3 \mathrm{~d}$ yazıcı ile üretim yapıldığı zaman kullanılabileceği öngörülmektedir. Ayrıca, tabaka şeklinde serilen kumun tabaka kalınlığı, katman sayısı gibi üretim parametreleri bu çalışmadan elde edilen diğer sonuçlardır.

- Basma gerilmesi ve şekil değiştirme değerlerine bakıldığı zaman, kum tane boyutunun azalmasıyla numunenin basma dayanımının artmakta ve birim şekil değiştirme değerinin ise azalmakta olduğu bulunmuştur. $\sigma_{\text {bas, } 55 / 60}=34,98 \mathrm{MPa}, \varepsilon_{55 / 60}=0,119$ değerleri ile en yüksek basma dayanımı ve en küçük şekil değiştirme değerine sahip malzemenin 55/60 numunesi olduğu bulunmuştur. Bu durumun sebebinin gözeneklilik oranından kaynaklandığı düşünülmektedir.

- Üretilen numuneler arasında en küçük tane boyutuna sahip 55/60 numunesinin, maksimum eğme dayanımı $\sigma_{\text {eğ, } 55 / 60}=11,06 \mathrm{MPa}$ ve maksimum eğme kuvveti ise $F_{55 / 60}=79,67 \mathrm{~N}$ olarak bulunmuştur. 55/60 numunesi diğer numunelere oranla maksimum eğme dayanımının ve eğme kuvvetinin daha yüksek olduğu bulunmuştur. Bu durumun sebebinin, 55/60 numunesinin gözeneklilik oranının daha az ve 55/60 numunesini oluşturan kumun reçine tarafindan 1slatılabilirliğinin daha iyi olmasından kaynaklandığı düşünülmektedir.

- Eğme testi yapılan numunelerin sahip olduğu sehim miktarları karşılaştırıldığında, en büyük sehim miktarına $\delta_{30 / 35}=0,359 \mathrm{~mm}$ ile 30/35 numunesinin sahip olduğu bulunmuştur. Bu sonuç, en sünek malzemenin 30/35 numunesi olduğunu göstermektedir. 30/35 numunesinin sünekliliğinin diğer numunelere oranla yüksek olmasının sebebinin, 30/35 numunesinde bulunan gözenekler içerisine kolayca giren reçine ve katalizörün kimyasal tepkimeye girerek gözenek çeperlerine iyi bir şekilde yapışmasından kaynaklandığı düşünülmektedir.

- Üretilen, 30/35 ve 40/45 numunelerinin maksimum eğme dayanımlarının $\sigma_{\text {eğ, } 30 / 35}=5,82 \mathrm{MPa}$ ve $\sigma_{\text {eğ,40/45 }}=5,81 \mathrm{MPa}$ olarak bulunmuştur. Bu iki numunenin eğme dayanımlarının birbirlerine yakın çıkma sebebinin, her iki numuneyi oluşturan kum tanelerinin 1slatılabilirliğinin birbirlerine yakın olmasından ve belirli bir tane çapından sonra kum tane boyutunun maksimum eğme dayanım değerini çok fazla etkilememesinden kaynaklandığı düşünülmektedir.

- Gözeneklilik sonuçlarına göre, malzeme yapısını oluşturan bileşenlerden biri olan kumun, tane boyutunun azalmasıyla, numunenin gözeneklilik oranının da azalmakta olduğu bulunmuştur. Bu durumunda, numune yapısını oluşturan kumun tane boyutu ne kadar büyük olursa, numune yapısında daha büyük boşluklar oluşmasına neden olmaktadır.

- Üretim yapılırken, furan reçinesi ve katalizör birbirlerine doğrudan karıştırılmamıştır. Şayet direk temas edilmesi durumunda şiddetli ekzotermik reaksiyon oluşmaktadır. Bu sebeple katalizör ve reçine kuma ayrı ayrı pulverize şekilde püskürtülmüştür.

- Üretimi yapılan numunelerin tamamen kürlenme süresi, ön denemeler sonucunda oda sıcaklığında 12 saat olarak bulunmuştur. Çalışmada kullanılan reçine, havada sertleşen furan reçinesi olduğu için üretim sonunda sinterleme yapılmamıştır. 


\section{KAYNAKLAR}

[1] ASTM F2792-12a, Standard Terminology for Additive Manufacturing Technologies, ASTM International: West Conshohocken, PA, USA, 2012,

[2] C.L. Weber, V. Peña, M.K. Micali, E. Yglesias, S.A. Rood, J.A. Scott, B. Lal, "The Role of the National Science Foundation in the Origin and Evolution of Additive Manufacturing in the United States,” IDA Science \& Technology Policy Institute, USA, Rap. IDA Paper P-5091, 2013.

[3] D. Çelik, "Üç boyutlu yazıcı tasarımı, prototipi ve tersine mühendislik uygulamaları," Yüksek lisans tezi, Endüstriyel Tasarım Mühendisliği Bölümü, Karabük Üniversitesi, Karabük, Türkiye, 2015.

[4] A. Çelebi, H. Tosun, A.Ç. Önçağ, "Hasarlı Bir Kafatasının Üç Boyutlu Yazıcı ile İmalatı ve İmplant Tasarımı," International Journal of 3D Printing Technologies and Digital Industry, c.1, s.1, ss. 27-35, 2017.

[5] K. Özsoy, B. Duman, "Eklemeli İmalat (3 Boyutlu Baskı) Teknolojilerinin Eğitimde Kullanılabilirliği," International Journal of 3D Printing Technologies and Digital Industry, c.1, s.1, ss. 36-48, 2017.

[6] B. Güler, K. Çetinkaya, "Endüstriyel Boyutlu Çift Başlı Kartezyen Tipi Üç Boyutlu Yazıcı Tasarımı ve Prototip Üretimi," International Journal of 3D Printing Technologies and Digital Industry, c.2, s.1, ss. 11-22, 2018.

[7] Ö. Elbaba, S. Sezer, H. Şahin, S. Dilibal, “Elastomerik Malzemelerin Katmanlı İmalatında Temel Parametrelerin Analizi," International Journal of 3D Printing Technologies and Digital Industry, c.2, s.1, ss. 69-75, 2018

[8] J.B. Lassiter III, M.C. Lieb, and T. Clay. , "Z Corporation,” Harvard Business School Case 801210, October 2000. (Revised April 2005.)

[9] STM Mühendislik \&Teknoloji \&Danışmanlık. (2018, 12 Ocak). Katmanlı imalat yöntemleri ve havactlk uygulamalarl. [Online]. Erişim: https://www.stm.com.tr/documents/file/Pdf/1.katmanli_imalat_teknolojileri_raporu_2016-08-03-1411-28.pdf/.

[10] M. Xia, J. Sanjayan, "Method of formulating geopolymer for 3D printing for construction applications," Materials and Design, vol. 110, pp. 382-390, 2016.

[11] Anonim, (12 Ocak 2018). [Online]. Erişim:

https://www.voxeljet.com/company/news/phenolic-resin-based-3d-printing-in-foundry-technology/.

[12] P.K. Gokuldoss, S. Kolla, J. Eckert, “Additive manufacturing processes: selective laser melting, electron beam melting and binder jetting - selection guidelines" Materials, vol. 10(6), 672, 2017, doi:10.3390/ma10060672. 
[13] Anonim, (12 Ocak 2018). [Online]. Erişim: https://www.rapidmade.com/large-format-3d-printingone-meter-vx1000-voxeljet/.

[14] Anonim, (12 Ocak 2018). [Online]. Erişim: http://www.inovasilis.com/urunkategori/silis-kum/.

[15] Anonim, (12 Ocak 2018). [Online]. Erişim: http://www.cukurovakimya.com.tr/dokum-recineri/.

[16] J.M.L. Reis, "Effect of textile waste on the mechanical properties of polymer concrete," Materials Research, vol. 12, no. 1, pp. 63-67, 2009.

[17] G. İnan Sezer, Ş. Yazıcı, "Polimer Katkılı Harçlarda Farklı Kür Koşullarının Dayanıma Etkisi," CBÜ Fen Bilimleri Dergisi, c. 11, s. 2, ss. 195-201, 2015.

[18] P. Mani, A.K. Gupta, S. Krishnamoorthy, "Comparative study of epoxy and polyester resinbased polymer concretes," International Journal of Adhesion and Adhesives, vol. 7, no. 3, pp. 157-163, 1987. 